\title{
Challenges of Railway Embankments Remediation
}

\author{
Mario Bačić1, Antun Juzbašić 2 \\ ${ }^{1}$ Faculty of Civil Engineering University of Zagreb, \\ fra Andrije Kačića Miošića 26, Zagreb, Croatia \\ mbacic@grad.hr \\ ${ }^{2}$ JET-SET d.o.o. \\ Kneza Ljudevita Posavskog 204, Vrbanja, Croatia
}

\begin{abstract}
In the absence of proper maintenance efforts, the railway infrastructure ageing process leads to generally poor network conditions. In common with many rail networks, there is a wish to increase capacity on the network while in same time infrastructure managers are dealing with the effects of climate change which can result in catastrophic failures. These climate impacts are most prominent on railway earthworks, especially earth embankments. Longer duration and more intense precipitation events result in number of embankment failures, including soil stability issues, excessive settlements of embankments, etc. All this significantly affects both safety and functionality of railway networks. Continuously increasing axle loads, along with poor drainage conditions and unfavourable geometry of these embankments, where their side slopes tend to be much steeper than modern highway slopes made in similar soils, make them extremely prone to failures. This paper presents several case studies of railway embankment failures occurred on Croatian railway lines, along with challenges that arose during the asset condition assessment, remediation design and remediation works. An insight into remediation contingences due to the specific nature of railway infrastructure is also given, encompassing different engineering aspects.
\end{abstract}

Keywords: railway embankments, embankment failure, climate change, remediation contingences

\section{Introduction}

Unlike the modern highway networks, major part of the European railway was built in the $19^{\text {th }}$ century, prior to the advent of modern design standards and specifications. This inevitably led to significantly lower safety of railway assets, not just in EU transit states, but also in developed ones. The ageing of the railway infrastructure, fuelled by the lack of clear strategies and non-investment atmosphere [1] has caused its gradual degradation and there is a strong need for risk assessment associated with this obsolete infrastructure, all with the aim of increasing safety and reducing the cost of rehabilitation. However, rehabilitation procedures still mostly remain as reactive procedures, rather than implementing proactive approach, which allows prioritization of the rail investments in both construction of new and remediation of existing networks. The decisions to perform asset maintenance are based on mostly visual observations, subjective judgments and choices which are ruled by available budgets, planned schedules or abrupt failures [2, 3]. In same time there is a common wish of many rail networks to increase capacity.

Along with ageing, both increased operational dynamic axle loading and varying environmental conditions such as more prominent climate impacts are known stressors to the infrastructure. This is especially case for the railway embankments, which are extremely vulnerable to climate impacts. In many parts of Europe, as well in Croatia, climate scenarios point to change of rainfall patterns, where the less precipitation events can be expected [4], but these will be more intense causing the rapid loading and increasing the failure potential. Additionally, these periods of intense precipitation will follow after the longer dry spells. This means that the aged railway embankments are influenced to the impact of such events as drying and cracking of near surface soils during dry periods, allowing rapid infiltration of water during rainfall, reducing the soil strength and causing sudden failure [5]. Earthworks on old railway networks are particularly prone to failure and do not offer comparable levels of capability and resilience to modern engineered slopes. Failure of a single asset results in potential fatalities, large replacement costs, the loss of service for sometimes extended periods and reputational damage. The aim of this paper is to demonstrate some examples of railway embankments in Croatia burdened by the different problems and causing a serious issue to the infrastructure managers. The most common 
issues are listed, followed by the procedures and investigation works for embankment overall condition assessment and by the rehabilitation challenges.

\section{Some Common Railway Embankment Problems}

The embankment related problems are usually conditioned by its overall geometry and construction materials. A diverse portfolio of steep embankment slopes poses a significant challenge for infrastructure managers, while the embankment construction procedures mostly included utilization of poorly graded local materials from adjacent cuttings, installed as non-compacted fill, in most cases with insufficient quality control. All this is fuelled by the mentioned changing environmental impacts and increase of railway traffic loading, which has a large influence on the probability of failure for certain failure mechanisms. Different human interventions can also cause the problems linked with railway embankments, such is the change of geometry for the excavation of drainage trenches on the toe of the embankment, or removal of vegetation and consequently its beneficial influence on embankment stability. The later one is often a case due to maintenance and to avoid interference of higher vegetation with lines of electrified railway lines. Smethurst et al. [6] note that the balance between reducing seasonal track movement and maintaining embankment stability might best be achieved by selectively removing high water demand tree species within a defined distance of influence, rather than clearing all trees from an embankment slope.

Some common railway embankment problems faced by infrastructure manager are shown in Figure 1. Here, the most common issues are linked with the stability of embankments and excessive settlement of railway tracks. In a limit state design framework, these represent the ultimate (ULS) and serviceability (SLS) limit states, respectively.

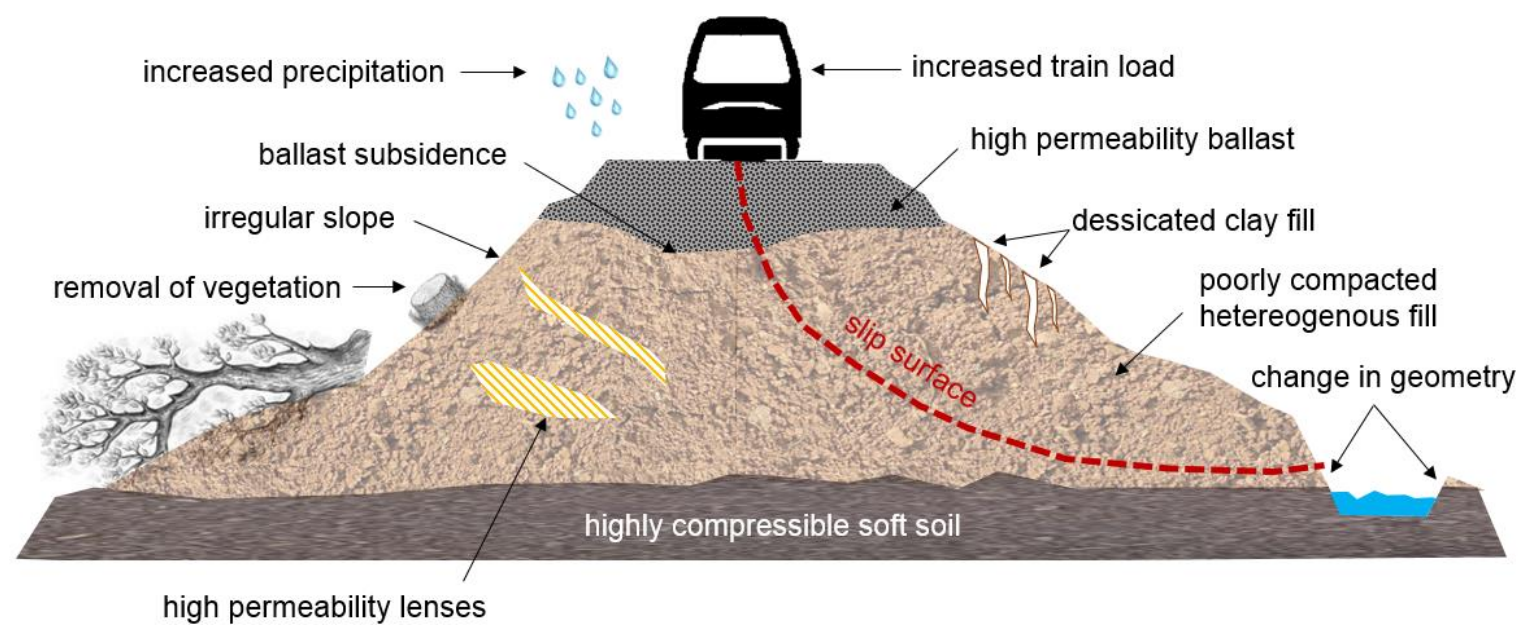

Fig. 1: Different factors affecting the railway embankments behaviour

The main influence on reaching Serviceability Limit State (SLS) is in geotechnical characteristics of a railway line substrata, where usually a soft soil layer is present. The term 'soft soil' is used for low consistency soil deposits characterized by a low shear resistance and high compressibility. The combination of poor soil characteristics with embankment and surcharge loads, produces critical settlements to the structure. The differential settlements of sleepers and tracks have a highly negative impact on the railway performance. The railway infrastructure supported by the embankment is particularly sensitive to small height changes. One example of exceedance of SLS is given for embankment on Croatian line R202 in chainage km 132, where accumulation of long-term settlements occurs, and where tampering (compensation by addition of ballast) activities are often conducted to fulfil serviceability criteria and maintain the operation of the line, see Figure 2a. Here, a $4 \mathrm{~m}$ high embankment was constructed over weak and very compressible soils as soft clay.

One of the most common embankment-related problem is exceedance of the ULS manifested as overall sliding of embankment slopes, due to loss of material strength and / or steep geometry. Since most of these embankments are constructed of low-permeability materials, the seasonal, shrink-swell volume change of railway embankments can 
reduce the strength of the clay fill soil and promote the progressive failure of embankment slopes. A rapid change of weather can cause rapid saturation of coherent materials, increasing pore pressures and leading to shear strength loss. This This is often case in last years, where high intensity snow events are followed by rapid thawing and consequential saturation. An example of the later, aided by the removal of slope vegetation, can be found on an embankment on Croatian line M202 in chainage km 515, see Figure 2b. Some other ULS-linked problems on existing embankment include sliding of stone cover of slopes due to poor binding between stones, cause by ageing and washing out of stone bonds, such was the case for the embankment on Croatian line M604 in chainage km 266, see Figure 2b.
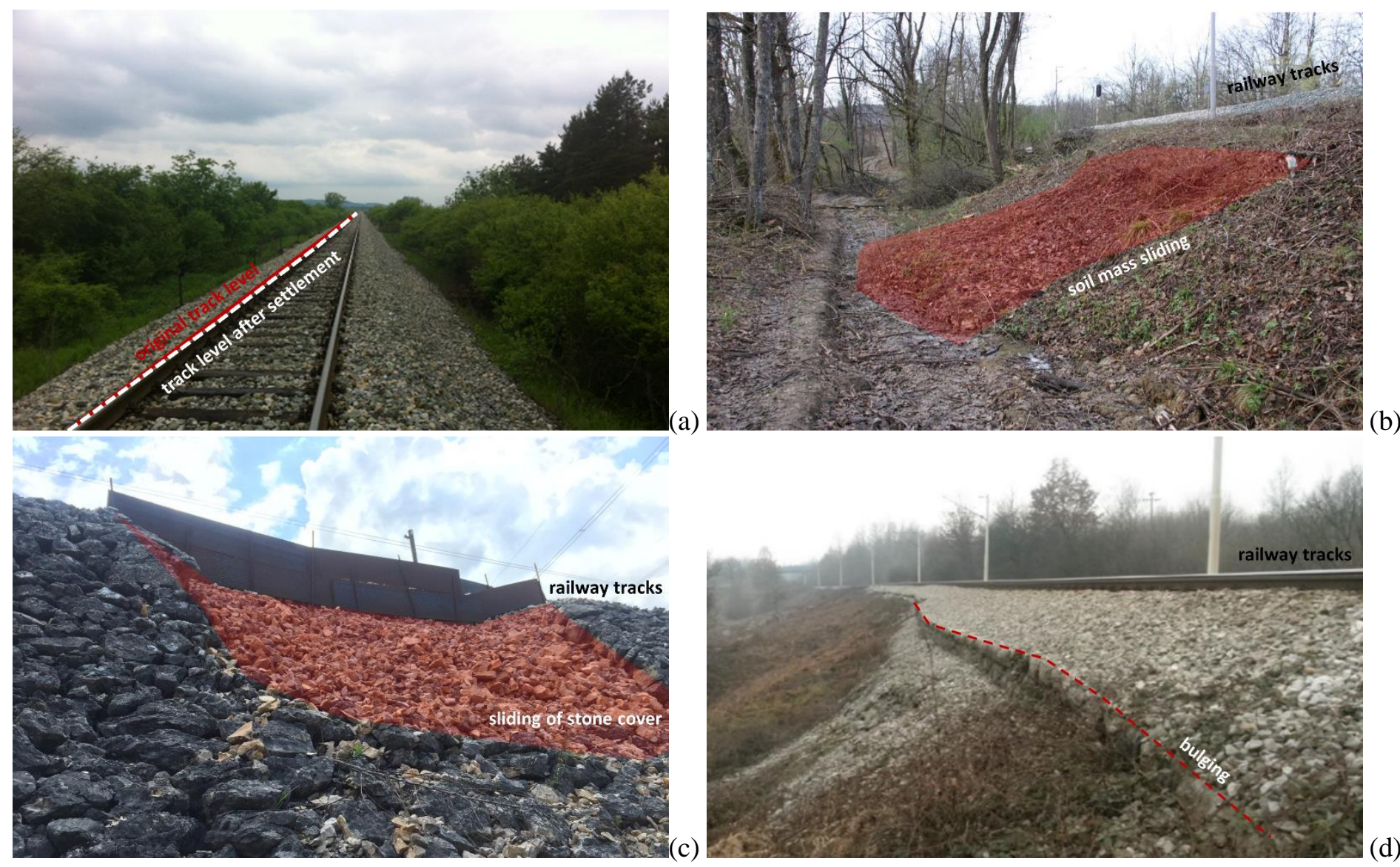

Fig. 2: Some of embankment-related issues: (a) large settlements, (b) overall stability loss, (c) sliding of slope stone cover, (d) settlement and stability issues due to poor drainage

Poor drainage of old railway embankments can affect both the SLS and ULS. The serviceability is affected by washing-out of fine particles leading to progressive settlements, while ULS is affected by increase of pore pressures leading to shear strength loss. An example of an embankment with extremely poor drainage characteristics is the embankment on Croatian line M202 in chainage km 499. Unlike the highway embankments which have well maintained road and toe, this embankment has a permeable ballast surface and no drainage leading to the concentrations of water and exacerbation of track bed problems.

\section{Embankment Condition Assessment Procedures}

Proper investigation works are crucial to evaluate the current condition, as well to design appropriate embankment strengthening measures. Investigation procedures for embankments usually pose a challenge for professionals, considering specifies of railway lines, especially where the optimization of investigation works is required because of the linear nature 
of these assets. In his paper on standards and quality in ground investigation, Norbury [7] notes that a chance of carrying out the 'right' investigation is conditioned by the fact that the planning needs to be made by suitably qualified professionals. He additionally stresses out that too many investigations are planned by non-specialists with the wrong questions asked and therefore answers not being received to the right questions.

The investigation works of already failed embankment differ from the works conducted to assess the condition necessary for evaluation of the critical limit states. These reactive investigation works are usually focused on a specific portion of an embankment where the failure occurred, while proactive works have to cover larger embankment sections. An example of latter is given by Kovačević et al. [5] where a categorization of the condition of $180 \mathrm{~km}$ of railway embankments across a Croatian network was conducted, having the non-destructive GPR investigation in focus for detection of ballast fouling, ballast pockets, anomalies such as animal burrows. The mentioned categorization served as a starting point for subsequent detailed investigation works and monitoring activities. Through early identification of problem or hot-spot locations, low-cost remediation can be applied and thus costs can be reduced and failures avoided. This enables detection of potential failures, before they are encountered by train drivers, as is usually the case.

Usually, prior to investigations, very little to none information exists on the material used for the construction of old embankments, as well on construction procedures. This lack of information presents a limitation in planning of investigation work programme, where desk study is of limited scope and where some preliminary investigations are usually not implemented. First, a detailed survey needs to be conducted to obtain the overall geometry of an embankment, along with all relevant details. In last years a significant progress was done in the field where large areas are covered in relatively short period through application of UAVs and photogrammetry technique. Traditional embankment testing methods include continuous borehole drilling which is basic geotechnical test that provides an insight into the geological structure of the underlying soil. By taking samples and conducting the laboratory test, an insight into the physical and mechanical characteristics of the soil can be obtained. In the case of founding an embankment on very soft or organic soils, in which the quality of drilling and collected samples is often insufficient, only in situ probing allows for obtaining reliable parameters for design calculations. These sounding methods can provide almost continues profile of a measured parameter, with better averaging over the soil mass than based on laboratory tests alone [8]. The traditional soil investigation methods have some limitations in terms of time and finances, and it is precisely these constraints that have been the motive for developing methods that, in addition to saving the aforementioned resources, will allow for larger volumes to be examined. Among these methods stand out geophysical methods that require a complex methodology and relatively advanced mathematics to interpret the measurement results. However, many of the information can be easily evaluated already at the surveyed location.

\section{Embankment Remediation Challenges}

To address the embankment issues by implementing appropriate rehabilitation measures, a designer must rely on several factors and must be aware of number of rehabilitation contingencies related to railway infrastructure. The contingencies, among others, include commonly encountered variations of geological conditions. These can be overseen by investigation works and can affect a design solution, so it is crucial that the designer is involved also during the rehabilitation works to properly evaluate these effects and to adapt the solution if necessary. Most of other limitations are similar to investigation work contingencies, considering unavailability of certain sections of railway lines for machinery, as well the impact of rehabilitation works on traffic disruption. Because of common necessity to conduct works under the traffic, a design must anticipate execution in several sections to limit both impact of traffic and to limit potential unwanted consequences. This impact of traffic must be taken into account during the design phase to verify if limit states are not exceeded even during construction. However, sometimes the full traffic closure is inevitable such as in case of construction gravel trenches below the line, or when it is necessary to install a culvert as part of rehabilitation solution.

The rehabilitation technique must be selected to ensure the long-term mechanical resistance and stability of railway embankment, while in same time designer should also take into account perennial issue of budget limitation which infrastructure manager needs to deal with. Several techniques of railway embankment rehabilitation, each with its own advantages and disadvantages, can be applied, depending on the problems which aims to be solved. The most 
common rehabilitation measure for ensuring the stability is redistribution of masses, including the slope angle reduction, construction increase of load at embankment toe, along with embankment material replacement. However, this kind of rehabilitation solution often comes with issues of cadastral parcels owned by the infrastructure managers, commonly next to the toe of the railway embankment. If property-legal relations are not to be changed, which is usually a requirement of infrastructure managers, a designer must consider a solution to remain into the existing parcel, making it difficult to apply most straightforward geometry-related rehabilitation measures. In that case additional measures such as gabion wall (Figure 3a) installed at line M202, chainage $\mathrm{km} \mathrm{515,} \mathrm{can} \mathrm{be} \mathrm{applied,} \mathrm{or} \mathrm{the} \mathrm{angle} \mathrm{of} \mathrm{the} \mathrm{slope} \mathrm{at} \mathrm{toe} \mathrm{should} \mathrm{be} \mathrm{steeper,} \mathrm{such}$ is the case for the embankment at line M202, chainage $\mathrm{km} 499$ (figure 3c).

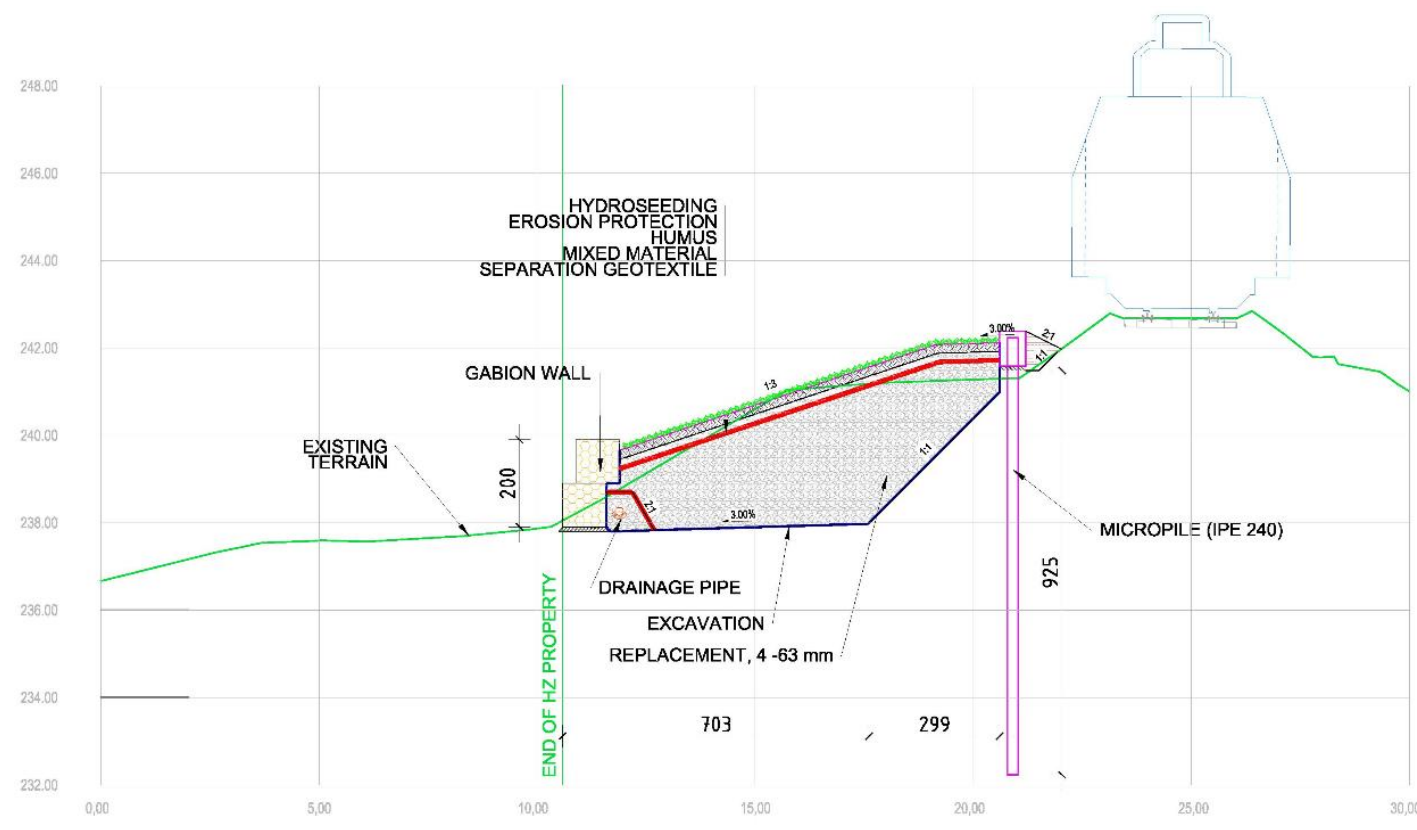

(a)

Fig. 3: cont. 


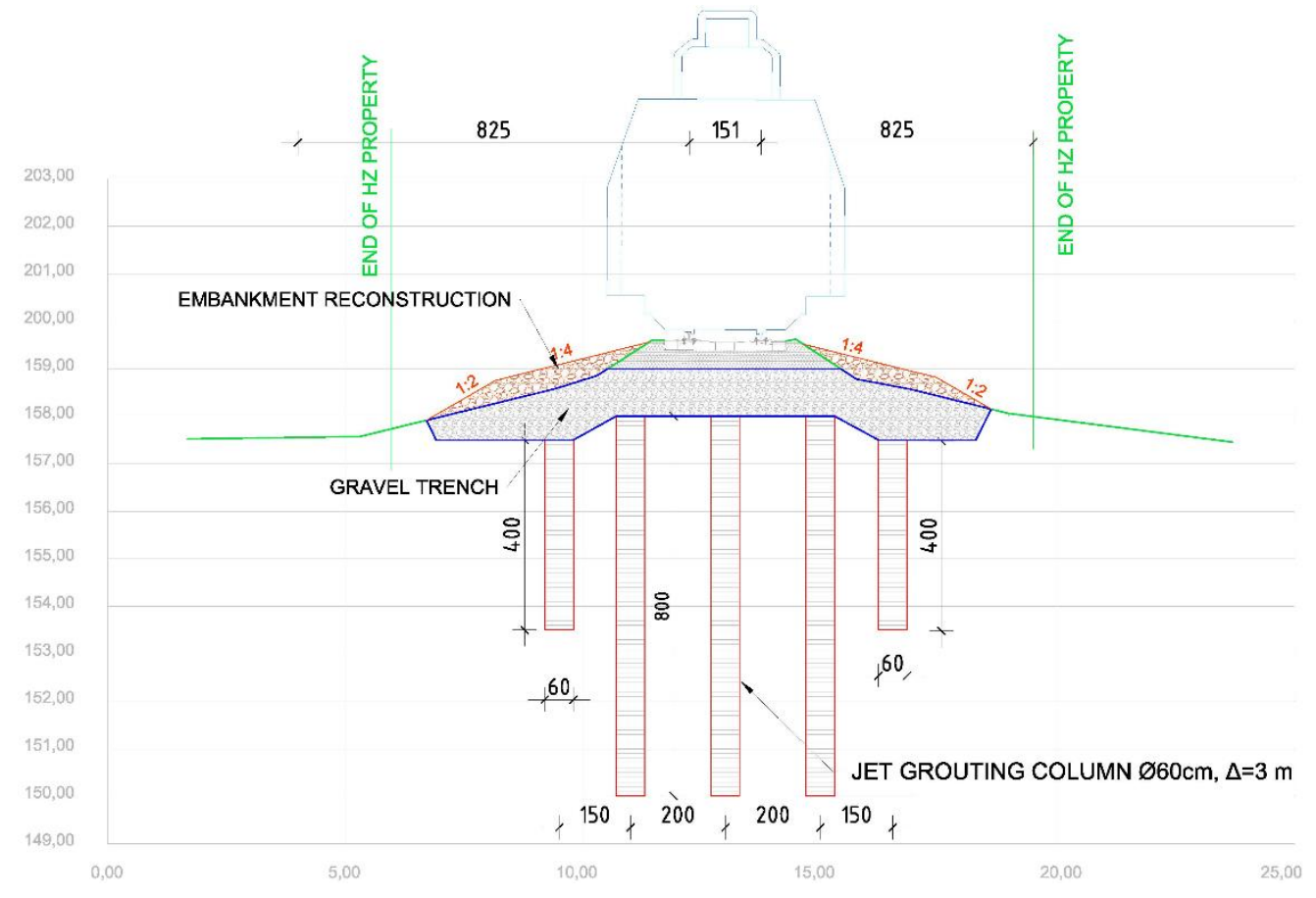

(b)

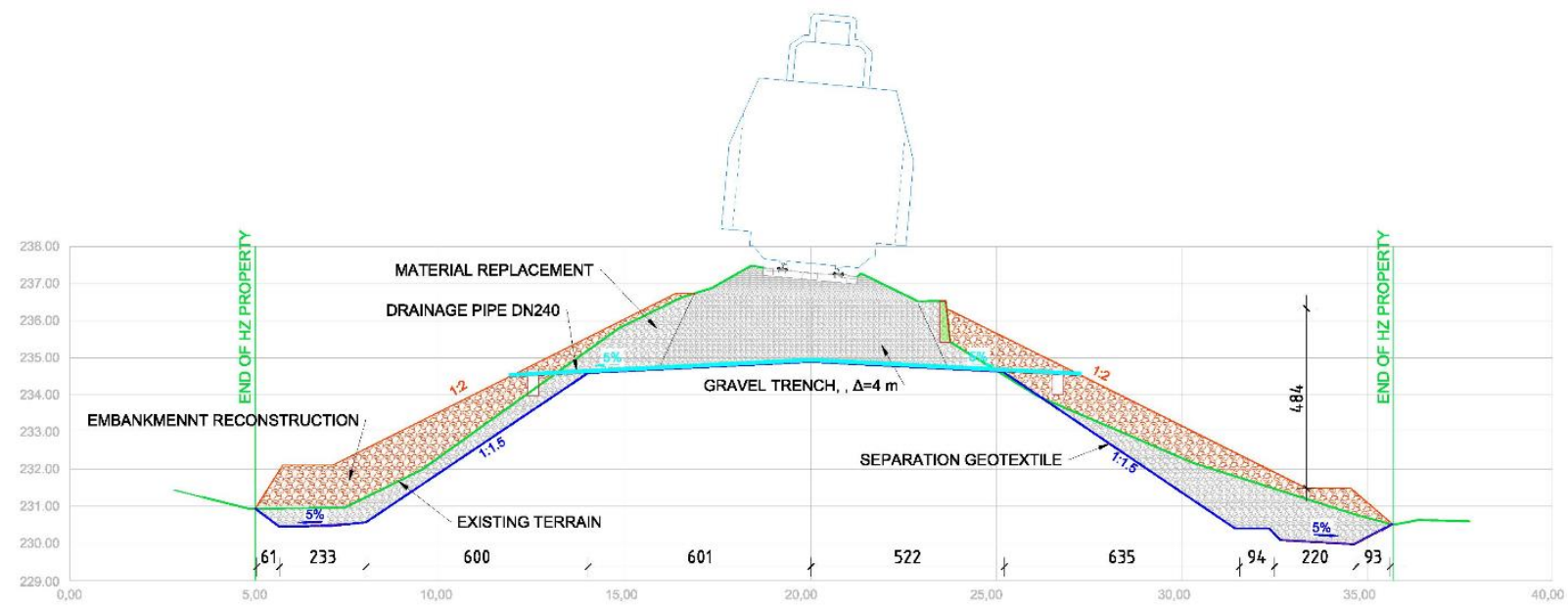

(c)

Fig. 3: Some remediation solutions for old railway embankments: material replacement with installation of a gabion wall at embankment toe (a), jet-grouting columns to enhance the soil properties thus reducing the embankment settlements (b), installation of gravel trenches to enhance the drainage characteristics of an embankment (c)

A proper drainage measures should be always considered during the rehabilitation design, to allow the controlled water flow and drainage of water outside the embankment zone.

If the problem is in soft subsoil which yields continuous settlements of the embankments and rail upper system, an adequate soil improvement method could be considered. Methods based on deep soil reinforcement include installation of granular columns or jet-grouting, with the latter one being more acceptable for existing embankments, since technology may not require complete removal of embankment body, such is the case for the embankment in chainage $\mathrm{km} 132$ on Croatian line R202, where the jet-grouting columns prevented further settlement of the embankment, see Figure 3c. 
Other factors which affect the rehabilitation of railway embankments include presence of both over-ground and underground utilities. While the over-ground usually implies visible electrified lines, where a switching of electric current may be required during the rehabilitation, under-ground utilities can pose a threat where no or inaccurate mapping of these utilities can lead to their damage, which can have far-reaching cost and time consequences. Also, a designer must be aware that all of the elements used for rehabilitation must be properly earthed if installed in vicinity of electrified lines. To secure a safe construction as well a long-term performance of rehabilitated embankment, a geotechnical monitoring program needs to be set-up. The monitoring will be used to quantitatively check the embankment performance and several monitoring techniques can be incorporated to evaluate both embankment surface deformation and subsurface deformation monitoring. Monitoring of earthworks is difficult, since they can be variable in terms of geometry and material properties, there can be local defects, they are often covered with vegetation that can make assessment and condition monitoring difficult, and there are multiple modes of failure, some of which are complex. The quality control/checks at all stages of construction, and construction supervision of railway embankment rehabilitation, must be considered.

\section{Conclusions}

The specific nature of railway embankments poses a challenge for conduction of investigation work and condition assessment, as well for design and implementation of rehabilitation measures. Professionals conducting investigation works, designers and contractors must be aware of number of rehabilitation contingencies related to railway infrastructure. In same time, the existing ageing railway embankments are prone to failure and do not offer comparable levels of capability and resilience to modern engineered slopes, and this mainly owes to the known stressors such are the more prominent climate impacts and increased operational dynamic axle loading. To obtain a better insight into railway embankment related problems faced by infrastructure manager, this paper presents some practical examples of stability issues of embankments and excessive settlement of railway tracks, as well the rehabilitation solution for these issues. In order to shift from omnipresent embankment reactive rehabilitation procedures, to the proactive approach, it is crucial to move forward from the decision making based solely on visual observations, subjective judgments and choices, ruled by available budgets, planned schedules or abrupt failures. Paper also give some guidelines for conduction of investigation work, design and implementation of measures.

\section{References}

[1] Kovacevic, M.S., Gavin, K., Stipanovic Oslakovic, I. and Bacic, M., "A New Methodology for Assessment of Railway Infrastructure Condition”, Transportation Research Procedia, vol.14, pp. 1930-1939, 2016. DOI: 10.1016/j.trpro.2016.05.160

[2] Dhillon, B. S., "Engineering maintenance: a modern approach". CRC Press, Boca Raton, 2002.

[3] Wu, Y., Qin, Y., Wang, Z. and Jia, L., "An UAV-Based Visual Inspection Method for Rail Surface Defects", Appl. Sci., Vol.8., No.7, 1028, 2018. DOI: https://doi.org/10.3390/app8071028

[4] Gavin, K.G. and Xue, J.F, "Use of a genetic algorithm to perform reliability analysis of unsaturated soil slopes", Geotechnique, Vol. 59, No. 6, 2009, pp. 545-549. DOI: 10.1680/geot.8.T.004

[5] Kovačević, M.S., Bačić, M., Stipanović, I. and Gavin, K, "Categorization of the Condition of Railway Embankments Using a Multi-Attribute Utility Theory", Applied Sciences-Basel, Vol.9, No. 23, 2019, ID: 5089, 17. DOI: 10.3390/app9235089.

[6] Smethurst, J.A., Briggs, K., Powrie, W., Ridley, A. and Butcher, D., "Mechanical and hydrological impacts of tree removal on a clay fill railway embankment", Geotechnique, Vol. 65, No. 11, 2019, pp. 869-882.

[7] Norbury, D., "Standards and quality in ground investigation; squaring the circle" Quarterly Journal of Engineering Geology and Hydrogeology, Vol. 50, 2007, pp. 212-230.

[8] Witold, B. and Godlewski, T., "Geotechnical design of railway embankments - requirements and challenges", KRYNICA 2018, MATEC Web of Conferences 262, 2019, 8 pgs. DOI: 10.1051/matecconf/201926211002. 